\title{
Preoperative QCT assessment of femoral head for assessment of femoral head bone loss
}

\author{
$\mathrm{CHEN} \mathrm{YI}^{1}, \mathrm{MANYI} W A N G^{2}, \mathrm{JIE} \mathrm{WEI}^{2}, \mathrm{JUN} \mathrm{WANG}^{2}, \mathrm{LING} \mathrm{WANG}^{3}$ and XIAOGUANG $\mathrm{CHENG}^{3}$ \\ ${ }^{1}$ Medical Center, Tsinghua University, Beijing 100084; Departments of ${ }^{2}$ Traumatic Orthopedics \\ and ${ }^{3}$ Radiology, Beijing Jishuitan Hospital, Beijing 100035, P.R. China
}

Received May 27, 2016; Accepted January 23, 2017

DOI: $10.3892 /$ etm.2017.4136

\begin{abstract}
We quantified differences in trabecular volumetric bone mineral density (BMD) of the femoral head between patients with proximal femoral fractures and healthy subjects in the control group by using quantitative computed tomography (QCT) with the purpose of providing guidance for the choice of head screw in the intramedullary nail fixation. Participants suffering from intertrochanteric fractures ( $n=536$ patients) were recruited. In addition, 497 fracture-free, age-matched cases were considered as the control group. The volumetric BMD of different regions of interest (ROI) in the proximal femur scanned by QCT were analyzed between the fracture and control groups. BMD of proximal femur in the fracture group was markedly lower than that in the control group. There were significant differences at distinct regions for male and female between the two groups. Furthermore, the trend of BMD changes among the femoral head, femoral neck and intertrochanter were not parallels in terms of their average value. In conclusion, osteoporosis has been demonstrated to be a main risk factor of the proximal femoral fracture. BMD value of proximal femur was often inconsistent with that of femoral head. Given this, preoperative QCT assessment plays an important role in choosing proper head screw in the intramedullary nail fixation.
\end{abstract}

\section{Introduction}

Hip fractures are among the most important health problems in the elderly. Intertrochanteric fracture constitutes one of the most common fractures of the hip, occurring mainly in elderly people with osteoporosis $(1,2)$. With ageing, it is estimated that

Correspondence to: Dr Jie Wei, Department of Traumatic Orthopedics, Beijing Jishuitan Hospital, 31 Xinjiekou East Street, Beijing 100035, P.R. China

E-mail: jie_wei1212@163.com

Key words: hip fracture, intertrochanteric fracture, femoral head, femoral neck, quantitative computed tomography, bone mineral density the number of hip fractures will still increse in the population. The aim of surgical treatment for the intertrochanteric fracture is the reduction and stable fixation of the fracture in order to recover the ability of immediate mobilization. Early mobilization could reduce the incidence of fatal complications for the elderly. Intramedullary nail is currently widely used in the treatment of unstable fractures, including proximal femoral nail antirotation (PFNA) and Gamma nail (3-5). For the choice of the head screw in the intramedullary nail fixation, the bone quality of femoral head is critically important. The lag screw of Gamma nail can exert compression effect at the fracture site. It requires good bone quality of femoral head to provide a sufficient gripping force. Spiral blade of PFNA can increase the bone density during hammering in the femoral head and it is more suitable for serious bone loss of the femoral head in the osteoporosis patients. The bone quality of femoral head is essential for the choice of head screw and better choice can decrease the risk of head screw cutting out and pulling out.

It has been widely reported that the dual-energy X-ray absorptiometry (DXA) and the quantitative computed tomography (QCT) were used to assess the bone mineral density (BMD) of femoral neck and intertrochanteric. DXA is generally used in clinical work to measure areal BMD at the proximal femur for the diagnosis of osteoporosis (6,7). Although DXA is widely used to evaluate BMD in clinical practice, it is well known that the method of DXA is inadequate for accurate estimation of bone mass. Spatial accuracy in measuring BMD and morphologic parameters of the proximal femur by using DXA is limited, because the DXA provides only plane 2-D images. Furthermore, due to the sheltering of acetabular, DXA cannot assess the accurate bone mass of femoral head. Unlike DXA image, the QCT can provide the reconstruct true three-dimensional images for measuring true morphologic features and BMD of trabecular bone of the femoral head (8-11). In this study, we aimed to quantify differences in trabecular BMD of the femoral head between patients with proximal femoral fractures and healthy subjects in the control group by using QCT and the conclusion may provide some guidance for the choice of head screw in the intramedullary nail fixation.

\section{Materials and methods}

Patients and volunteers. We recruited participants who suffered intertrochanteric fractures in Beijing Jishuitan 
Table I. Characteristics of the two groups.

\begin{tabular}{lcc}
\hline Parameters & Fracture group & Control group \\
\hline No. of patients & 536 & 497 \\
Male/Female & $202 / 334$ & $212 / 285$ \\
Age (years) & $65.8 \pm 17.3$ & $66.2 \pm 10.4$ \\
\hline
\end{tabular}

Hospital from January 2013 to December 2014. There were total of 536 patients with fractures (fracture group, average age was $65.8 \pm 17.3$ years) entered into the study. In addition, we recruited 497 cases of fracture-free, age-matched controls (control group, average age was $66.2 \pm 10.4$ years) as part of a larger study. Descriptive characteristics for the subjects are provided in Table I. This study was approved by the Ethics Committee of Beijing Jishuitan Hospital. Patients agreed to the use of their samples in scientific research.

CT scan acquisition. The subjects were scanned by using a multidetector CT scanner (LightSpeed CT; GE Medical Systems, Fairfield, CT, USA) with standard protocol scanning from the iliac crest to the knee. Scanning parameters were $120 \mathrm{kVp}$, $350 \mathrm{~mA}$, slice thickness was $2.5 \mathrm{~mm}$, and $512 \times 512$ matrix in a spiral reconstruction mode with a $36-\mathrm{cm}$ field of view.

Image processing. We measured volumetric $\mathrm{BMD}\left(\mathrm{g} / \mathrm{cm}^{3}\right)$ using commercial software (QCT Pro; Mindways Software, Inc., San Francisco, CA, USA) at the proximal femur. A midcoronal multi-planar reconstruction (MPR) view of the uninjured contralateral proximal femur in the fracture group, and of the bilateral proximal femur in the control group was reconstructed using commercially available image analysis software (Virtual Place-M; Medical Imaging Laboratory, Tokyo, Japan). Trabecular BMD in the region of interest (ROI) was measured by tracing the trabecular region.

We used in-house software developed using the Visualization Toolkit (VTK 5.6; Kitware Inc., Clifton Park, NY, USA) to calibrate the CT-measured density values based on the calibration phantom and rescaled the images using cubic interpolation to $1.0-\mathrm{mm}$ isotropic voxels.

Determination of ROI. CT images were used to determine the ROI in the proximal femur. Femural head was divided into three parts: Proximal, middle and distal femoral head. Fig. 1 shows: line a, femoral neck axis through the femoral head center; line $b$, tangent to the femoral head and perpendicular to the line a along with intersection of point $\mathrm{A}$; line $\mathrm{c}$, the boundary of femoral head and femoral neck; line d, midline of femoral neck; and line e, midline of intertrochanter. Five regions in different color in Fig. 1 represent five ROI of proximal, middle and distal femoral head, femoral neck and intertrochanter. BMD of femoral head was the mean values of proximal, middle and distal femoral head. Each area included nine slices for the CT images.

Statistical analysis. Comparisons of the two data sets were analyzed by t-test, and data with more than two variables were analyzed by two-way repeated measure-ANOVA with
Table II. Comparison of bilateral BMD at different regions for subjects in the control group.

\begin{tabular}{lrrr}
\hline Regions & Left & Right & P-value \\
\hline BMD at head $\left(\mathrm{mg} / \mathrm{cm}^{3}\right)$ & $232.5 \pm 39.3$ & $228.4 \pm 38.4$ & 0.753 \\
BMD at neck $\left(\mathrm{mg} / \mathrm{cm}^{3}\right)$ & $77.1 \pm 39.4$ & $74.9 \pm 41.2$ & 0.641 \\
BMD at intertrochanter & $73.6 \pm 44.7$ & $74.1 \pm 43.8$ & 0.683 \\
$\left(\mathrm{mg} / \mathrm{cm}^{3}\right)$ & & & \\
\hline
\end{tabular}

BMD, bone mineral density.

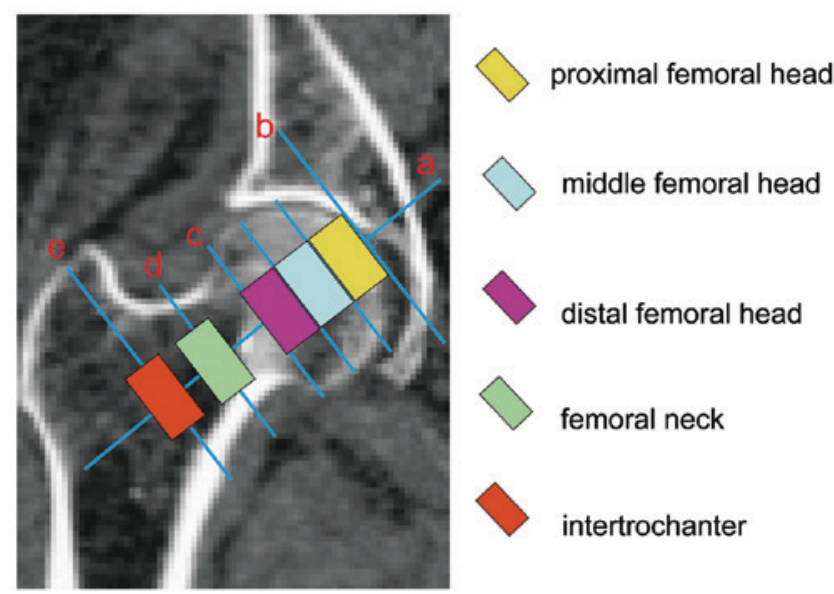

Figure 1. Five different regions scanned by QCT: Proximal femoral head; middle femoral head; distal femoral head; femoral neck and femoral intertrochanter. QCT, quantitative computed tomography.

Tukey's post hoc test analysis. All data are plotted as the mean \pm standard error.

\section{Results}

No significant difference existed in the age between the two groups $(\mathrm{P}>0.05)$ (Table I). For control group, results showed no marked difference of BMD between left and right proximal femur for all regions $(\mathrm{P}>0.05)$. However, BMD in different ROIs was significantly different. Results revealed that BMD of femoral head was remarkably larger than that of femoral neck and intertrochanter in the control group (Table II).

Further, we compared BMD between the two groups in different ROIs and found that BMD of proximal femur in the fracture group was obviously lower than that in the control group $(\mathrm{P}<0.05)$ (Table III). Furthermore, the BMD differences at distinct regions for male and female were statistically significant between two groups (Tables IV and V). The BMD of proximal femoral head was higher than other two parts of the head, but not statistically significant in the control group $(\mathrm{P}>0.05)$. However, in the fracture group, the BMD of proximal femoral head was significantly lower than the distal part of the head $(\mathrm{P}<0.05)$ (Fig. 2).

For some subjects in the two groups, we found that the trend of BMD changes among the femoral head, femoral neck and intertrochanter were not parallels in terms of their average value. In the control group, there were 81 male and 51 female 
Table III. Comparison of BMD at different regions in the two groups.

\begin{tabular}{lrrr}
\hline Regions & $\begin{array}{c}\text { Control } \\
\text { group (left) }\end{array}$ & $\begin{array}{c}\text { Trochanteric } \\
\text { fracture }\end{array}$ & P-value \\
\hline BMD at head $\left(\mathrm{mg} / \mathrm{cm}^{3}\right)$ & $232.5 \pm 39.3$ & $161.2 \pm 39.4$ & $<0.001$ \\
BMD at neck $\left(\mathrm{mg} / \mathrm{cm}^{3}\right)$ & $77.1 \pm 39.4$ & $26.9 \pm 37.5$ & $<0.001$ \\
BMD at intertrochanter & $73.6 \pm 44.7$ & $27.6 \pm 31.3$ & $<0.001$ \\
$\left(\mathrm{mg} / \mathrm{cm}^{3}\right)$ & & & \\
\hline
\end{tabular}

BMD, bone mineral density.

Table IV. Comparison of BMD at different regions for male subjects in the two groups.

\begin{tabular}{lrrr}
\hline & $\begin{array}{c}\text { Control } \\
\text { group } \\
(\mathrm{N}=212)\end{array}$ & $\begin{array}{c}\text { Trochanteric } \\
\text { fracture } \\
(\mathrm{N}=202)\end{array}$ & P-value \\
\hline Regions & & & \\
\hline BMD at head $\left(\mathrm{mg} / \mathrm{cm}^{3}\right)$ & $241.5 \pm 41.5$ & $165.2 \pm 41.8$ & $<0.001$ \\
BMD at neck $\left(\mathrm{mg} / \mathrm{cm}^{3}\right)$ & $79.9 \pm 38.8$ & $27.7 \pm 38.3$ & $<0.001$ \\
BMD at intertrochanter & $75.6 \pm 44.7$ & $29.9 \pm 36.1$ & $<0.001$ \\
$\left(\mathrm{mg} / \mathrm{cm}^{3}\right)$ & & & \\
\hline
\end{tabular}

BMD, bone mineral density.

Table V. Comparison of BMD at different regions for female subjects in the two groups.

\begin{tabular}{lrrr}
\hline & $\begin{array}{c}\text { Control } \\
\text { group } \\
(\mathrm{N}=285)\end{array}$ & $\begin{array}{c}\text { Trochanteric } \\
\text { fracture } \\
(\mathrm{N}=334)\end{array}$ & P-value \\
Regions & $221.7 \pm 43.8$ & $156.2 \pm 37.6$ & $<0.001$ \\
\hline BMD at head $\left(\mathrm{mg} / \mathrm{cm}^{3}\right)$ & $25.4 \pm 38.9$ & $<0.001$ \\
BMD at neck $\left(\mathrm{mg} / \mathrm{cm}^{3}\right)$ & $75.1 \pm 39.4$ & $25.6 \pm 30.9$ & $<0.001$ \\
BMD at intertrochanter & $70.8 \pm 43.9$ & & \\
$\left(\mathrm{mg} / \mathrm{cm}^{3}\right)$ & & &
\end{tabular}

BMD, bone mineral density.

subjects who had different trends of change between the femoral head and femoral neck (male, 81/212; female, 51/285), and 20 male and 56 female subjects between the femoral head and intertrochanter (male, 20/212; female, 56/285). Moreover, in the fracture group, there were 44 male and 91 female subjects in the femoral head and femoral neck (male, 44/202; female, 91/334), and 41 male and 110 female subjects in the femoral head and intertrochanter (male, 41/202; female, 110/334) (Table VI).

\section{Discussion}

This study was aimed at quantifying the differences in trabecular BMD among the femoral head, neck and intertrochanteric
Table VI. BMD of proximal femur and femoral head are not parallels.

\begin{tabular}{lccccc}
\hline & \multicolumn{2}{c}{ Control ICR } & & \multicolumn{2}{c}{ Fracture ICR } \\
\cline { 2 - 3 } \cline { 5 - 6 } Regions & Male & Female & & Male & Female \\
\hline $\begin{array}{l}\text { Between head and } \\
\text { neck, \% }\end{array}$ & 38.1 & 18.0 & & 22.0 & 27.1 \\
$\begin{array}{l}\text { Between head and } \\
\text { intertrochanter, \% }\end{array}$ & 9.5 & 19.5 & & 20.3 & 32.9 \\
\hline
\end{tabular}

BMD, bone mineral density; ICR, inconsistent rate.

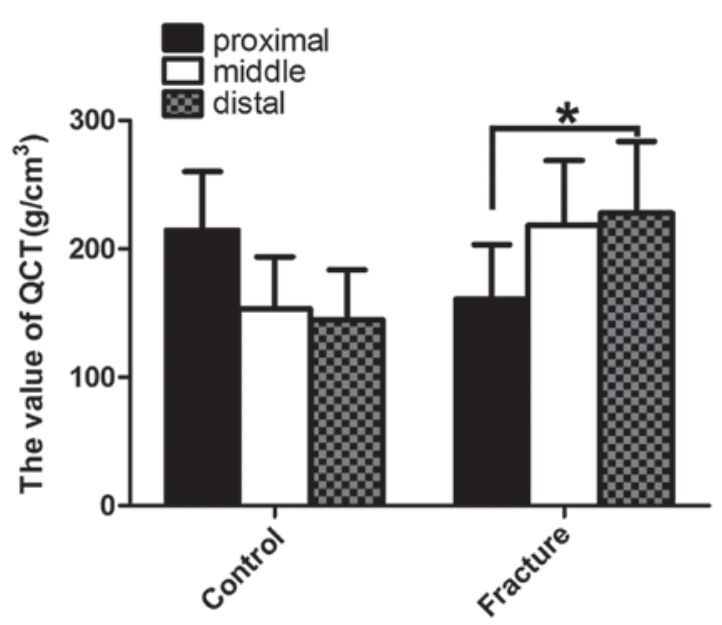

Figure 2. Comparison of different femoral head regions for subjects in the two groups. The BMD of proximal femoral head was higher than the other two parts of the head, but not statistically significant in the control group; in the fracture group, the BMD of proximal femoral head was significantly lower than the distal part of the head. BMD, bone mineral density. $\mathrm{P}<0.05$.

for the healthy subjects in the control group and patients in the fracture group by using quantitative computed tomography to provide some guidance for the choice of head screw in the intramedullary nail fixation.

In the literature, it has been reported that helical blade behaves differently to a screw in the femoral head. Both screw systems (SHS and Gamma 3) and helical blades (PFNA and trochanteric fixation nail (TFN) are, respectively, suitable for different populations. A biomechanical study has shown that the blade device is more prone to cutout by comparing threaded screw with helical blade constructs in a model of pertrochanteric fracture fixation using polyurethane femoral heads. The main reason described was that the blade device presents a lesser contact surface to the cancellous bone in the axial direction due to its shape of helical blade. Furthermore, they reported an axial contact surface of $75 \mathrm{~mm}^{2}$ for the PFNA blade and $300 \mathrm{~mm}^{2}$ for the Gamma 3 screw (12). Xu et al found no cut-out in the Gamma and PFNA groups, but in their study, the femoral head condition was not described (13). It has been reported that the initiating factors of mechanical failure in femoral cutout include the position of screw or blade, quality of bone and inappropriate rehabilitation $(14,15)$. It has been reported that both screw systems and helical blades 
fail if the screw or blade was not optimally positioned, and thus that the center-center position in the head of femur of any kind of lag screw or blade is to be achieved to minimize rotation of the femoral head and to prevent further mechanical complications (16-19). For the choice of the head screw in the intramedullary nail fixation, the bone quality of femoral head is critically important. The lag screw requires good bone quality of femoral head, and high density bone to provide a sufficient gripping force $(5,20,21)$. On the contrary, the spiral blade of PFNA is more suitable for serious bone loss of the femoral head in the osteoporosis patients. The main reason is that it can increase the bone density during hammering in the femoral head $(3,4)$. Thus, the bone quality of femoral head is essential for the choice of head screw and a better choice can decrease the risk of head screw cutting out and pulling out.

In our study, we showed that the BMD of hip for male are greater than that for females, and therefore evaluation of BMD values after dividing subjects into male and female groups would be preferable $(22,23)$. It has been reported that the BMD of elderly was smaller than that of young by QCT and DXA due to osteoporosis, metabolism and hormone (23-25). Thus, this study was an age-matched study in order to avoid the impact of age factor on the BMD of hip, and there was no significant difference in the age between control and fracture groups. There was significant difference in the proximal femoral BMD between the control and fracture groups. It illustrated that osteoporosis was an independent factor for the hip fracture and was consistent with previous studies $(26,27)$.

There is no perfect method for assessment of bone quality of femoral head. Lack of theoretical basis for the choice of head screw in the intramedullary nail fixation is an important issue to be solved in the clinical practice (28). It has been reported that QCT has become a useful research tool for analyzing hip geometry and measuring BMD (29-31). However, it has not yet been widely used in clinical practice $(27,32)$. We believe that the QCT can provide the reconstructed true three-dimensional images for measuring true morphologic features and BMD of trabecular bone of the femoral head, which was not influenced by the bone overlapping around the femoral head by the 2-D images such as DAX $(30,31,33)$. Furthermore, QCT as an important preoperative assessment can provide better guidance for the choice of head screw in the intramedullary nail fixation.

There are some limitations to our findings. First, the measured BMD was of the hip not on the fractured side, but on the contralateral side. However, we have compared the sides in the control group. Thus, the BMD of the proximal femur on both sides generally are considered similar in this study. Second, the results of our study cannot be used to identify risk factors for hip fractures, because the relationship between BMD and mechanical feature of the hip remains unclear. Thirdly, the range of normal value in the healthy population did not result from large number of samples. Thus, further research of expanding the normal sample size is in progress.

In conclusion, osteoporosis is a risk factor for the proximal femoral fracture, and the BMD of proximal femoral head could not alone represent the femoral head. Thus, the preoperative QCT assessment of femoral head is indispensable option for the assessment of femoral head bone loss and it may provide some guidance for the choice of head screw in the intramedullary nail fixation.

\section{References}

1. Xue L, Zha L, Chen Q, Liang YJ, Li KR, Zhou Z, Guan JL, Qin H and Li YP: Randomized controlled trials of proximal femoral nail antirotation in lateral decubitus and supine position on treatment of intertrochanteric fractures. Sci World J 2013: 276015,2013

2. Foss NB and Kehlet H: Hidden blood loss after surgery for hip fracture. J Bone Joint Surg Br 88: 1053-1059, 2006.

3. Yang YH, Wang YR, Jiang SD and Jiang LS: Proximal femoral nail antirotation and third-generation Gamma nail: which is a better device for the treatment of intertrochanteric fractures? Singapore Med J 54: 446-450, 2013.

4. Ostrum RF, Tornetta P III, Watson JT, Christiano A and Vafek E: Ipsilateral proximal femur and shaft fractures treated with hip screws and a reamed retrograde intramedullary nail. Clin Orthop Relat Res 472: 2751-2758, 2014.

5. McCormack R, Panagiotopolous K, Buckley R, Penner M, Perey B, Pate G, Goetz T and Piper M: A multicentre, prospective, randomised comparison of the sliding hip screw with the Medoff sliding screw and side plate for unstable intertrochanteric hip fractures. Injury 44: 1904-1909, 2013.

6. Watts NB: Fundamentals and pitfalls of bone densitometry using dual-energy X-ray absorptiometry (DXA). Osteoporos Int 15: $847-854,2004$

7. Tauchmanovà L, Nuzzo V, Del Puente A, Fonderico F, Esposito-Del Puente A, Padulla S, Rossi A, Bifulco G, Lupoli G and Lombardi G: Reduced bone mass detected by bone quantitative ultrasonometry and DEXA in pre- and postmenopausal women with endogenous subclinical hyperthyroidism. Maturitas 48: 299-306, 2004.

8. Shim VB, Pitto RP and Anderson IA: Quantitative CT with finite element analysis: towards a predictive tool for bone remodelling around an uncemented tapered stem. Int Orthop 36: 1363-1369, 2012.

9. Ramamurthi K, Ahmad O, Engelke K, Taylor RH, Zhu K, Gustafsson S, Prince RL and Wilson KE: An in vivo comparison of hip structure analysis (HSA) with measurements obtained by QCT. Osteoporos Int 23: 543-551, 2012.

10. Kalkwarf HJ, Laor T and Bean JA: Fracture risk in children with a forearm injury is associated with volumetric bone density and cortical area (by peripheral QCT) and areal bone density (by DXA). Osteoporos Int 22: 607-616, 2011.

11. Ito M, Wakao N, Hida T, Matsui Y, Abe Y, Aoyagi K, Uetani M and Harada A: Analysis of hip geometry by clinical CT for the assessment of hip fracture risk in elderly Japanese women. Bone 46: 453-457, 2010.

12. Born C, Karich B, Bauer C, von Oldenburg G and Augat P: Hip screw migration testing: first results for hip screws and helical blades utilizing a new oscillating test method. J Orthop Res 29: 760-766, 2011.

13. Xu Y, Geng D, Yang H, Wang X and Zhu G: Treatment of unstable proximal femoral fractures: comparison of the proximal femoral nail antirotation and gamma nail 3. Orthopedics 33: 473, 2010.

14. O'Malley NT, Deeb AP, Bingham KW and Kates SL: Outcome of the dynamic helical hip screw system for intertrochanteric hip fractures in the elderly patients. Geriatr Orthop Surg Rehabil 3: 68-73, 2012.

15. Frei HC, Hotz T, Cadosch D, Rudin M and Käch K: Central head perforation, or 'cut through,' caused by the helical blade of the proximal femoral nail antirotation. J Orthop Trauma 26: e102-e107, 2012.

16. Goffin J, Pankaj P and Simpson A: The importance of lag screw position for the stabilization of trochanteric fractures with a sliding hip screw: a subject-specific finite element study. J Orthop Res 31: 596-600, 2013.

17. Kuzyk PR, Zdero R, Shah S, Olsen M, Waddell JP and Schemitsch EH: Femoral head lag screw position for cephalomedullary nails: a biomechanical analysis. J Orthop Trauma 26: 414-421, 2012.

18. Schwarzkopf R, Takemoto RC, Kummer FJ and Egol KA: Helical blade vs telescoping lag screw for intertrochanteric fracture fixation. Am J Orthop (Belle Mead NJ) 40: 452-456, 2011. 
19. Geller JA, Saifi C, Morrison TA and Macaulay W: Tip-apex distance of intramedullary devices as a predictor of cut-out failure in the treatment of peritrochanteric elderly hip fractures. Int Orthop 34: 719-722, 2010.

20. Laohapoonrungsee A, Arpornchayanon O and Phornputkul C: Two-hole side-plate DHS in the treatment of intertrochanteric fracture: Results and complications. Injury 36: 1355-1360, 2005.

21. Verettas DA, Ifantidis P, Chatzipapas CN, Drosos GI, Xarchas KC Chloropoulou P, Kazakos KI, Trypsianis G and Ververidis A: Systematic effects of surgical treatment of hip fractures: gliding screw-plating vs intramedullary nailing. Injury 41: 279-284, 2010.

22. Keyak JH, Sigurdsson S, Karlsdottir G, Oskarsdottir D, Sigmarsdottir A, Zhao S, Kornak J, Harris TB, Sigurdsson G, Jonsson BY, et al: Male-female differences in the association between incident hip fracture and proximal femoral strength: a finite element analysis study. Bone 48: 1239-1245, 2011.

23. Marshall LM, Zmuda JM, Chan BK, Barrett-Connor E, Cauley JA, Ensrud KE, Lang TF and Orwoll ES; Osteoporotic Fractures in Men (MrOS) Research Group: Race and ethnic variation in proximal femur structure and BMD among older men. J Bone Miner Res 23:121-130, 2008.

24. Nicks KM, Amin S, Melton LJ III, Atkinson EJ, McCready LK, Riggs BL, Engelke K and Khosla S: Three-dimensional structural analysis of the proximal femur in an age-stratified sample of women. Bone 55: 179-188, 2013.

25. Ohnaru K, Sone T, Tanaka K, Akagi K, Ju YI, Choi HJ, Tomomitsu T and Fukunaga M: Hip structural analysis: a comparison of DXA with CT in postmenopausal Japanese women. Springerplus 2: 331, 2013.

26. Vochteloo AJ, Borger van der Burg BL, Röling MA, van Leeuwen DH, van den Berg P, Niggebrugge AH, de Vries MR, Tuinebreijer WE, Bloem RM, Nelissen RG, et al: Contralateral hip fractures and other osteoporosis-related fractures in hip fracture patients: incidence and risk factors. An observational cohort study of 1,229 patients. Arch Orthop Trauma Surg 132: 1191-1197, 2012.
27. Lau EM, Suriwongpaisal P, Lee JK, Das De S, Festin MR, Saw SM, Khir A, Torralba T, Sham A and Sambrook P: Risk factors for hip fracture in Asian men and women: the Asian osteoporosis study. J Bone Miner Res 16: 572-580, 2001

28. Herman A, Landau Y, Gutman G, Ougortsin V, Chechick A and Shazar N: Radiological evaluation of intertrochanteric fracture fixation by the proximal femoral nail. Injury 43: 856-863, 2012.

29. Nishiyama KK, Ito M, Harada A and Boyd SK: Classification of women with and without hip fracture based on quantitative computed tomography and finite element analysis. Osteoporos Int 25: 619-626, 2014.

30. Khoo BC, Brown K, Zhu K, Pollock M, Wilson KE, Price RI and Prince RL: Differences in structural geometrical outcomes at the neck of the proximal femur using two-dimensional DXA-derived projection (APEX) and three-dimensional QCT-derived (BIT QCT) techniques. Osteoporos Int 23: 1393-1398, 2012.

31. Maeda Y, Sugano N, Saito M and Yonenobu K: Comparison of femoral morphology and bone mineral density between femoral neck fractures and trochanteric fractures. Clin Orthop Relat Res 469: 884-889, 2011.

32. Walker MD, Saeed I, McMahon DJ, Udesky J, Liu G, Lang T and Bilezikian JP: Volumetric bone mineral density at the spine and hip in Chinese American and White women. Osteoporos Int 23: 2499-2506, 2012.

33. Liu XS, Cohen A, Shane E, Yin PT, Stein EM, Rogers H, Kokolus SL, McMahon DJ, Lappe JM, Recker RR, et al: Bone density, geometry, microstructure, and stiffness: relationships between peripheral and central skeletal sites assessed by DXA, HR-pQCT, and cQCT in premenopausal women. J Bone Miner Res 25: 2229-2238, 2010. 